\title{
Factors Affecting Ventriculo-Peritoneal Shunt Failure in Children: A Comprehensive Review
}

\author{
Dr. N.V.S. Sunil Kumar ${ }^{*}$, Dr. Prakash Rao Gollapudi², Dr. K Srinivas ${ }^{3}$
}

\author{
${ }^{1}$ Assistant Professor of Neurosurgery, Gandhi Medical College and Hospital, Secunderabad, Telangana, India \\ ${ }^{2}$ Professor of Neurosurgery, Gandhi Medical College and Hospital, Secunderabad, Telangana, India \\ ${ }^{3}$ Professor and HOD of Neurosurgery, Gandhi Medical College and Hospital, Secunderabad, Telangana, India
}

DOI: $10.36347 /$ sjams.2020.v08i09.010

| Received: 03.09.2020 | Accepted: 11.09.2020 | Published: 12.09.2020

*Corresponding author: Dr. NVS Sunil Kumar

Abstract

Ventriculoperitoneal shunt (VPS) placement is one of the most commonly performed neurosurgical procedures and is necessary to treat most forms of hydrocephalus in children. These may be more common in developing countries due to poor economic conditions and a dearth of available resources. The shunt malfunction in paediatric patients may be caused by number of reasons, including obstruction, infection, pseudocyst formation and bowel perforation. This paper highlights the various factors affecting the successful outcome of VPS in children.

Keywords: Hydrocephalus, ventriculoperitoneal shunt, children, CSF, pseudocyst.

Copyright @ 2020: This is an open-access article distributed under the terms of the Creative Commons Attribution license which permits unrestricted use, distribution, and reproduction in any medium for non-commercial use (NonCommercial, or CC-BY-NC) provided the original author and source are credited.

\section{INTRODUCTION}

A ventriculoperitoneal shunt (VPS) is surgical equipment that relieves pressure on the brain caused due to accumulation of fluid. The VP shunting is a surgical procedure that is mainly done to treat a condition called hydrocephalus (Figure 01). This condition occurs when excess cerebrospinal fluid (CSF) collects in the brain's ventricles. CSF cushions the brain and protects it from injury inside the skull. The fluid acts as a delivery system for nutrients that brain needs, and it also takes away waste products. Normally, CSF flows through these ventricles to the base of the brain. The fluid then bathes the brain and spinal cord before it's reabsorbed into the blood. When this normal flow is disrupted, the buildup of fluid can create harmful pressure on the brain's tissues, which can damage the brain [1]. It is then advised to surgically place VP shunts inside one of the brain's ventricles to divert fluid away from the brain and restore normal flow and absorption of CSF. Excess fluid can build up around the brain for a number of reasons, including:

1. Overproduction of CSF

2. Poor absorption of CSF by the blood vessels

3. Blockages preventing fluid from flowing throughout the brain

Blockages are the most common cause of hydrocephalus. The cysts, tumours or inflammation in the brain can impede the normal flow of CSF and create an unsafe accumulation. Among the procedures performed for hydrocephalus, cerebrospinal fluid (CSF) diversion with insertion of ventriculoperitoneal (VP) shunt remains the most popular method in pediatric patients [2, 3]. Newer methods for treatment of hydrocephalus have also emerged with the most notable being endoscopic third ventriculostomy (ETV)[4]. ETV is considered to be the preferred treatment for noncommunicating hydrocephalus, atleast in older children, especially those with aqueductal stenosis [5, 6]. However, the effectiveness of ETV remains questionable in cases of hydrocephalus secondary to infective etiologies, hydrocephalus associated with meningomyelocele [7] and hydrocephalus in infants [8]. Unfortunately, complications related to VPS placement are also common, and multiple shunt revisions are almost expected throughout a patient's lifetime. Sometime VPS may become a cause of frustration and anxiety for patients, caregivers, and neurosurgeons alike. The failure rates of VPS have been estimated at approximately $10.9-23.7 \%$ within the first year after initial shunt placement $[9,10]$, with most researches [11] reporting a significantly large number of shunt revisions and replacements in pediatric patients compared to adults. In one of the study [12] conducted over 64 pediatric patients followed for 15 years, only $15.4 \%$ of patients did not require a revision during the period of follow up, and $17.3 \%$ of patients required 3 or more revisions. Wu Y et al. [13] Applied the database of the Office of Statewide Health Planning and development to identify 14,355 patients who received a VPS during the time of 1990-2000. The results showed 
the highest rate of shunt malfunction in neonates, followed by children, with adults having the lowest rates of shunt malfunction. The major independent risk factor for VPS complications in children is the type of hydrocephalus, with a significantly more risk linked with congenital and obstructive hydrocephalus compared to non-communicating hydrocephalus. Moreover male gender and low socioeconomic status were associated with an increased risk of VPS complications [14].

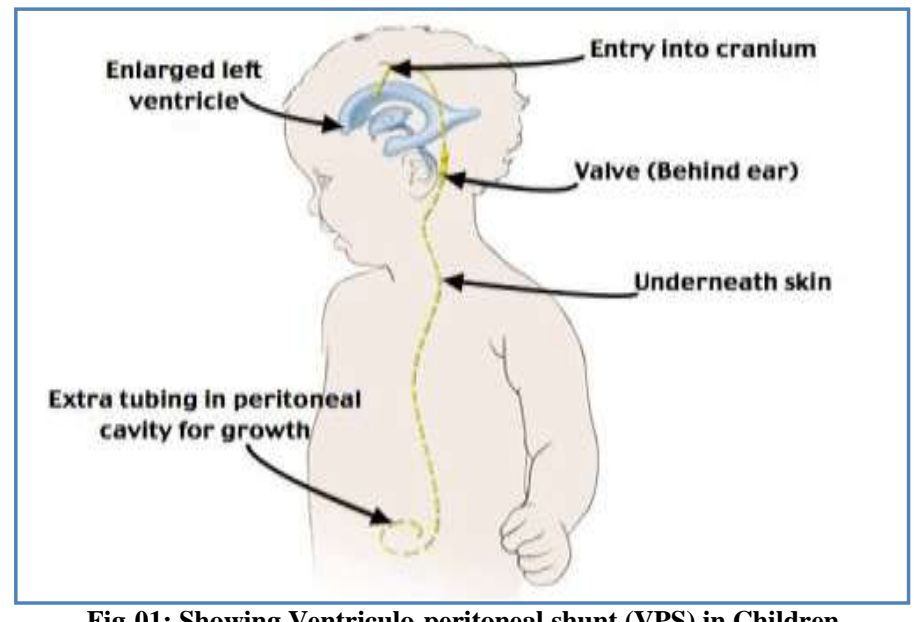

Fig-01: Showing Ventriculo-peritoneal shunt (VPS) in Children

Inspite of major advancements in VPS including design of valve, improved sterile techniques prevention of shunt malfunction has failed to demonstrate significant improvement over the past few years in children. The frequency of VPS complications in pediatric patients ranged from $45 \%$ to $59 \%$ in different reports $[15,16]$. The various factors affecting VPS failure in children can be broadly categories as:

\section{Infections of VP shunt}

It is the second most common cause of shunt malfunctioning, reported in approximately $8-14 \%$ of pediartric patients who undergo VPS placement [17]. The risk factors for shunt infection include young age, postoperative CSF leak, glove holes during shunt handling [18], African American race [19], public insurance, previous shunt infections and etiology of intraventricular hemorrhage. The highest risk for shunt infections was reported in premature neonates in whom the immune system is not fully developed. The majority of shunt infections occur within the first few weeks to several months after VPS placement [18]. Mostly patients will present with symptoms of infection, such as fever, however, this is not always the case. Patients with shunt malfunction due to any cause may present with nausea, vomiting, fever and headache although fever is more common in patients with shunt infection. McClinton et al. [20] noted the presence of fever and neutrophil count $>10 \%$ in the ventricular fluid had a specificity of $99 \%$, a positive predictive value of $94 \%$, and a positive probability of test $92 \%$ for predicting shunt infection. The most common causative organisms isolated from infected shunts in order of frequency are Staph epidermidis, Staph aureus, and gram negative rods [20, 21]. Staph epidermidis and Staph aureus are common skin flora, and infection typically occurs during shunt placement due to contamination from the skin. Thus, infections due to these organisms usually present relatively early after shunt placement. Standard therapy for shunt infection typically involves removal of the infected hardware and initiation of intravenous antibiotic therapy. A study [22] by pediatric neurosurgeons in the US showed that the large number of surgeons prefer to remove the infected shunt and place an external ventricular drain, while a smaller number prefer to externalize the infected shunt. Antibiotic impregnated catheters are a new strategy to prevent shunt infections from occurring. Raffa et al. [23] studied the incidence of infections in VP shunt in pediatric patients younger than one year and found that the rate of infection in the patients with antibiotic impregnated shunts was $9 \%$ while that in patients with standard shunt catheters it was $34 \%$.

\section{Obstruction of VP shunt}

VP Shunt catheter obstruction is the most common cause shunt malfunction. This obstruction can occur in the proximal catheter part, within the valve, or within the distal catheter, but, most of the studies [24, 25 ] proved that the most common site of obstruction site is the proximal catheter. Basically there are two types of valves used in VPS: programmable and nonprogrammable. In a study [24] after adjusting for age and etiology of hydrocephalus, it was found that programmable valves were associated with a relative risk reduction of shunt revision of 0.54 and that too in proximal catheter obstruction only. It could be due to the ability of the programmable valves to prevent overdrainage by means of non-invasive adjustments, which would theoretically prevent debris from being pulled into the proximal catheter.

Also the proximal catheter part of VP shunt may become clogged with parenchyma of brain as it is 
passed from the cortex into the brain ventricle during its surgical placement. Other theories hold that the proximal catheter may be blocked with pieces of choroid plexus when placed near the foramen of Monroe. Dickerman et al. [25] studied 115 shunt revisions performed at their institution to see if placement of the proximal catheter within the anterior horn of the lateral ventricle, farthest from the choroid plexus would be associated with a lower rate of shunt malfunction at 6 months, but this association was not found, although they did find the lowest rate of shunt malfunction to occur among patients with normal pressure hydrocephalus (NPH). These authors theorized that the patients with NPH had large ventricles, so proximal catheters were less likely to become blocked with choroid plexus.

Another important cause of VP shunt obstruction is the debris, because of blood and proteinaceous fluid may slowly accumulate within and eventually block the thin catheter tubing. This is supported by the findings of few studies [26] that showed that shunt malfunction was slightly more frequent among patients of hydrocephalus with intracranial hemorrhage.

The shunt obstruction diagnosis is mostly done with a combination of CT, shunt series, and shunt tapping or lumbar puncture (LP). The CT is likely to show increased ventricular size and LP may be suggestive of an elevated opening pressure, but this is not always the case [27]. Rocque et al. [28] noted that poor flow of CSF during a shunt tap had a $92 \%$ positive predictive value of proximal shunt obstruction.

\footnotetext{
Abdominal Pseudocyst

Abdominal pseudocyst is a rare complication reported in 1 to $44 \%$ of VPS patients [29]. It is often a late complication, with most cases occurring after a year or more of VPS placement or revision. Pseudocysts are formed due to collections of fluid around the tip of the distal catheter part of VPS which are surrounded by a fibrous tissue wall without an epithelium covering. They are believed to arise because of the effect of inflammation and abdominal adhesions that may occur with infections of shunt or due to multiple abdominal surgeries [30]. The most common clinical feature of a VP shunted patient with an abdominal pseudocyst is abdominal pain and distention with a palpable mass, although rarely neurological symptoms may be present. Sometimes, abdominal pseudocysts are hepatic pseudocysts, which can occur when the distal catheter tubing shifts to the surface of the liver and induces chronic irritation and inflammation, leading to right upper quadrant pain worsening after meals which may be accompanied by elevated liver enzymes [31]. The diagnosis of abdominal pseudocysts is made with either ultrasonography or abdominal CT scan. Dabdoub et al. [32] found pseudocyst recurrence in $18.8 \%$ of children
}

in whom the distal catheter was repositioned into a nonperitoneal space.

\section{Perforation of Bowel}

Bowel perforation by catheter tubing during VPS placement is estimated to occur in 0.1 and $0.6 \%$ cases. Most common presentation is protrusion of the tip of the distal catheter through the anus. In children, the majority of cases of bowel perforation occurs by the distal catheter, this could be due to the fact that children are having a relatively thin bowel wall, especially with myelomeningocele in whom innervation of the bowel wall may be insufficient [33].

The stiffness of the catheter tubing is also an important factor which contributes for bowel perforation during VPS. One study [34] compared the stiffness of three common shunt catheters, the Medtronic, Chhabra, and the Codman bactiseal shunt catheters, the results showed that Chhabra shunt catheters are the least stiff among the three; however they do have the highest frictional force.

Bowel perforation by catheter tubing has also occurred due to allergy to silicone. Although it is rare, but patients with such an allergy who receive VPS could develop bowel and abdominal wall perforations and other skin erosions around the distal tip of catheter.

\section{Overdrainage and subdural hematoma}

The formation of subdural collections and subdural hematoma can occur after VP shunting procedures as a result of overdrainage of CSF. The subdural hematoma formation incidence is $5 \%$ in high pressure hydrocephalus patients. One study [35] found serious over-drainage to be significantly more frequent in in NPH patients with an opening pressure of $>16 \mathrm{~cm}$ of water compared to those with a lower opening pressure. This suggests that patients with NPH and higher ICPs may be more sensitive to increased CSF drainage and thus more likely to develop subdural hematoma. The development of programmable shunt valves has offered a major advantage in treating symptoms of over drainage and subdural hematoma formation without the need for surgery in many cases.

\section{Conclusion}

The VP Shunt malfunction continues to be a common neurosurgical problem in children with shunted hydrocephalus, often leading to lengthy hospital stays. To prevent morbidity, early detection and proper management are key. VPS obstruction, which most often occurs in the proximal catheter, is the most common cause of VPS malfunction while hardware infection is the second most common. With continued advancements in shunt systems and infection prevention, morbidity resulting from shunt complications may continue to be reduced. 


\section{REFERENCES}

1. Al-Tamimi YZ, Sinha P, Chumas PD, Crimmins D, Drake J, Kestle J. Ventriculoperitoneal shunt 30day failure rate: a retrospective international cohort study. Neurosurgery. 2014;74:29-34.

2. Bhasin RR, Chen MK, Pincus DW. Salvaging the "lost peritoneum" after ventriculoatrial shunt failures. Childs Nerv Syst. 2007; 23:483-486.

3. Pudenz RH. The surgical treatment of hydrocephalus - an historical review. Surg Neurol. 1981;15:15.

4. Jallo GI, Kothbauer KF, Abbott IR. Endoscopic third ventriculostomy. Neurosurg Focus 2005;19:E11.

5. Jones RFC, Stening WA, Brydon M. Endoscopic third ventriculostomy. Neurosurgery. 1990;26:8292.

6. Hopf NJ, Grunert P, Fries G, Resch KDM, Perneczky A. Endoscopic third ventriculostomy: outcome analysis of 100 consecutive procedures. Neurosurgery. 1999;44:795-806.

7. Teo C, Jones R. Management of hydrocephalus by endoscopic third ventriculostomy in patients with myelomeningocele. Pediatr Neurosurg. 1996;25:57-63.

8. Warf BC, Tracy S, Mugamba J. Long-term outcome for endoscopic third ventriculostomy alone or in combination with choroid plexus cauterization for congenital aqueductal stenosis in African infants. J Neurosurg Pediatr. 2012;10:108111.

9. Khan F, Shamim MS, Rehman A, Bari WE, Analysis of factors affecting ventriculoperitoneal shunt survival in pediatric patients, Childs Nerv. Syst. 2013;29:791-802.

10. Khan F, Rehman S. Shamim, Bari ME, Factors affecting ventriculoperitoneal shunt survival in adult patients, Surg. Neurol Int. 2015;6:25.

11. Reddy GK, Bollam P, and Caldito G. Long term outcomes of ventriculoperitoneal shunt surgery in patients with hydrocephalus. World Neurosurg. 2014;81:404-410.

12. Stone JJ, Walker CT, Jacobson M, Phillips V, Silberstein HJ. Revision rate of pediatric ventriculoperitoneal shunts after 15 years, J. Neurosurg. Pediatr. 2013;11:15-19.

13. Wu Y, Green NL, Wrensch MR, Zhao S, Gupta N. Ventricluoperitoneal shunt complications in California: 1990 to 2000, Neurosurgery. 2007;61:557-562.

14. Paff M, Alexandru-Abrams D, Muhonen M, Loudon W. Ventriculoperitoneal shunt complications: A review. Interdisciplinary Neurosurgery. 2018;13:66-70.

15. Crnich CJ, Safdar N, Maki DG. Infections associated with implanted medical devices. Antibiotic and chemotherapy: antiinfective agents and their use in therapy. 2003;8:575-618.

16. Di Rocco C, Marchese E, Velardi F. A survey of the first complication of newly implanted CSF shunt devices for the treatment of nontumoral hydrocephalus. Cooperative survey of the 19911992 Education Committee of the ISPN. Child's nervous system: ChNS: official journal of the International Society for. Pediatr Neurosurg. 1994;10:321.

17. Rotim K, Miklic P, Paladino J, Melada A, Marcikic M, Scap M. Reducing the incidence of infection in pediatric cerebrospinal fluid shunt operations, Childs Nerv. Syst. 1997;13:584-587.

18. Kulkarni AV, Drake JM, Lamberti-Pasculli M. Cerebrospinal fluid shunt infection: a prospective study of risk factors, J. Neurosurg. 2001;94:195201.

19. Simon TD, Hall M, Riva-Cambrin J, Albert JE, Jefferies HE, LaFleur B, Dean JM, Kestle JRW. Infection rates following initial cerebrospinal fluent shunt placement across pediatric hospitals in the United States, J. Neurosurg. Pediatr. 2009;4:156165 .

20. McClinton D, Carraccio R. Englander. Predictors of ventriculoperitoneal shunt pathology, Pediatr. Infect. Dis. J. 2001;20:593-597.

21. McGirt MJ, Zaas A, Fuchs HE, George TM, Kaye K, Sexton DJ. Risk factors for pediatric VPS infection and predictors of infectious pathogens, Clin. Infect. Dis. 2003;36:858-862.

22. Whitehead WE, Kestle JRW, Treatment of cerebrospinal fluid shunt infections: results from a practice survey of the American Society of Pediatric Neurosurgeons, Pediatr. Neurosurg. 2001;35:205-210.

23. Raffa G, Marseglia L, Gitto E, Germano A. Antibiotic-impregnated catheters reduce ventriculoperitoneal shunt infection rate in highrisk newborns and infants, Childs Nerv. Syst. 2015 http://dx.doi.org/10.1007/s00381-015-2685-7

24. McGirt MJ, Buck II DW, Sciubba D, Woodworth GF, Carson B, Weingart J. Adjustable vs setpressure valves decrease the risk of proximal shunt obstruction in the treatment of pediatric hydrocephalus, Childs Nerv. Syst. 2007;23:289295.

25. Dickerman RD, McConathy WJ, Stevens QE, Jolley JT, Schneider S, Mittler MA. Failure rate of frontal versus parietal approaches for proximal catheter placement in ventriculoperitonal shunts: revisited, J. Clin. Neurosci. 2005;12(7):781-783.

26. Notarianni C, Vannemreddy P, Caldito G, Bollam $\mathrm{P}$, Wylen E, Willis B. Congenital hydrocephalus and ventriculoperitoneal shunts: influence of etiology and programmable shunts on revisions, J. Neurosurg. Pediatr. 2009;4:547-552.

27. Miller JP, Fulop SC, Dashti SR, Robinson SR, Cohen AR. Rethinking the indications for the ventriculoperitoneal shunt tap, J. Neurosurg. Pediatr.2008;1:435-438.

28. Rocque BG, Lapsiwala S, Iskandar B. Ventricular shunt tap as a predictor of proximal shunt 
malfunction in children: a prospective study, J. Neurosurg. Pediatr. 2008;1:439-443.

29. Rainov N, Schobess HV, Burkert W. Abdominal CSF pseudocysts in patients with ventriculoperitoneal shunts. Report of fourteen cases and review of the literature, Acta Neurochir. 1994;127(1-2):73-78.

30. Ohba S, Kinoshita Y, Tsutsui M, Nakagawa T, Shimizu K, Murakami TH. Formation of abdominal cerebrospinal fluid pseudocyst: case report, Neurol. Med. Chir. 2012;52:838-842.

31. Daboub CB, Fontoura EA, Santos EA, Romero PC, Diniz CA. Hepatic cerebrospinal fluid pseudocyst: a rare complication of ventriculoperitoneal shunt, Surg. Neurol. Int. 2013;4:1-62.

32. Dabdoub CB, Dabdoub CF, Chaves M, Villarroel MJ, Furrufino JL, Coimbra A, Orlandi BM. Abdominal cerebrospinal fluid pseudocyst: a comparative analysis between and adults, Childs Nerv. Syst.2014;30:579-589.

33. Sathyanarayana S, Wylen EL, Baskaya MK, Nanda A. Spontaneous bowel perforation after ventriculoperitoneal shunt surgery: case report and a review of 45 cases, Surg. Neurol. 2000; 54:388396.

34. Muthoni thiong'o G, Luzzio C, Albright AL. Ventriculoperitoneal shunts perforations of the gastrointestinal tract, J. Neurosurg. Pediatr. 2015; $1-6$.

35. Khan Q, Wharen RE, GreWal SS, Thomas CS, Deen HG, Reimer R, Van Gerpen JA, Crook JE, Graff-radford NR. Overdrainage shunts complications in idiopathic normal-pressure hydrocephalus and lumbar puncture opening pressure, J. Neurosurg. 2013;1(19):1498-1502. 